\title{
A Study of Sandstone Permeability Anisotropy Through Fractal Concept
}

\author{
Yosaphat Sumantri ${ }^{1,2, *}$, Pudji Permadi \\ ${ }^{1}$ Department of Petroleum Engineering, Universitas Pembangunan Nasional "Veteran" Yogyakarta, Yogyakarta, Indonesia \\ ${ }^{2}$ Department of Petroleum Engineering, Institut Teknologi Bandung, Bandung, Indonesia
}

Email address:

yos.sumantri@upnyk.ac.id (Y. Sumantri)

${ }^{*}$ Corresponding author

\section{To cite this article:}

Yosaphat Sumantri, Pudji Permadi. A Study of Sandstone Permeability Anisotropy Through Fractal Concept. American Journal of Science, Engineering and Technology. Vol. 3, No. 2, 2018, pp. 34-45. doi: 10.11648/j.ajset.20180302.12

Received: August 8, 2018; Accepted: August 28, 2018; Published: October 12, 2018

\begin{abstract}
Most correlation equations of rock permeability are usually based on the Euclidean geometry concept. Pore geometry and structure of most porous rocks are very complex, therefore non-Euclidean geometry concept, e.g. fractal theory, is needed to handle such a complexity. This paper presents a new equation for sandstone permeability involving other properties and fractal dimensions of pore space and surface. The equation is derived by combining Newton's Law of viscosity, Darcy equation, and fractal geometry concept. It is shown that parameters such as tortuosity, internal surface area, and shape factor can be replaced by fractal dimensions. As natural porous media are mostly anisotropic, this study enables us to identify factors that affect the anisotropy. Eighteen sandstone samples with porosity and permeability range from 21 to $37 \%$ and 2.76 to 3,644 millidarcies, were employed in this study. The pore space and surface fractal dimensions for each orthogonal direction for each sample was determined by box counting method. The results of this study demonstrate that calculated directional permeability of the high permeability samples is very close to the measured one after corrections were made for pore sizes of less than one micron. This finding suggests that micropores of the samples may be a major factor not contributing to fluid flow. For the low and medium permeability samples, however, an additional pore geometrical correction is needed. The additional correction factor is considerably different for different directions of fluid flow, indicating that the anisotropy is due to the difference in directional pore structural characteristics.
\end{abstract}

Keywords: Permeability, Tortuosity, Hydraulic Diameter, Fractal Dimension, Anisotropy

\section{Introduction}

Permeability is one of the most important petrophysical properties in petroleum engineering field. It determines the hydraulic capability of reservoir rocks in transmitting hydrocarbons. Naturally, pore systems of reservoir rocks are so complex that many internal pore characteristics may influence permeability of the rocks. Kozeny [1] and Carman [2] were probably the first two researchers who proposed a solution to the problems of complexity of porous media in predicting permeability. The approach used by these two researchers was to combine Poiseulle law for capillary pipes with Darcy equation. However, the resulting equation still required an empirical parameter so called pore shape factor to overcome irregularity of pore shape. The weaknesses of the equation have been comprehensively discussed [3-6] and some improvements were made [6-11]. It is the fact that the original Kozeny-Caman equation was derived by assuming porous media as a bundle of capillary pipes having Euclidian geometry.

Considerations of the development of both fractal theory $[12,13]$ and the complexity of pore morphology have driven many researchers to solve problems of fluid flow in porous media. Among the researchers are [10, 14-27].

Furthermore, it is believed that reservoir rocks are naturally anisotropic, meaning that permeability is directional dependent. The ratio of the highest permeability value to the lowest one for a given petroleum reservoir could range from about 1 to more than $5[28,29]$. Such a characteristic is of importance in reservoir engineering studies dealing with the fluid flow. To the best knowledge of the authors based on 
exhaustive review performed, no study has investigated the fractal characters of pore systems from different directions. The objective of this work is to study the differences of pore structure in terms of fractal dimension for three orthogonal directions. To this end, fractal concept, Newton law and Darcy equation are combined to develop a novel permeability equation considering rock anisotropy. A number of cubical samples of real sandstones having measured porosity is employed. Permeability of each sample is measured for each orthogonal direction. Several thin sections are sliced from each side of the sample in preparing 2-D thin-section images. For each orthogonal direction, the fractal dimension of the images is determined by using a box counting method. Comparisons between calculated permeability and measured one are then made. Any difference resulted between the two will be analyzed and discussed to arrive at the conclusion.

\section{Derivation of Equation for Fractal Porous Media}

\subsection{Fluid Flow in a Fractal Pipe}

The Newton viscosity law stated that a fluid has a viscosity of one poise when force of one dyne is needed to maintain a velocity difference of one $\mathrm{cm} / \mathrm{second}$ between two parallel planes of fluid with one $\mathrm{cm}$ in distance. Newton's viscosity law can be written as [30]:

$$
F_{s}=-\mu A_{c} \frac{d v}{d \ell}
$$

where: $F_{s}=$ the force working perpendicular to $l$ needed to

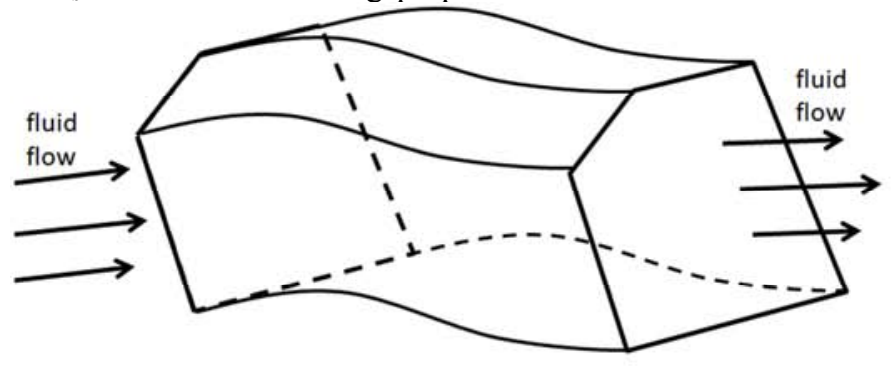

(a)

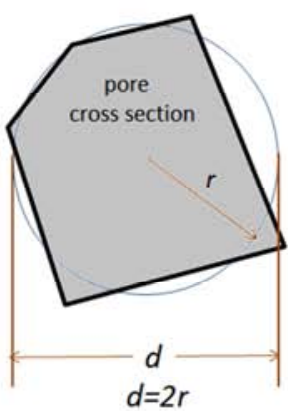

(b)

$$
\frac{\Delta p}{2 \mu L_{e}} \delta^{D p-D s} d \delta=-d v
$$

maintain a velocity difference between two fluid planes (dynes), $\mu=$ the fluid viscosity (poise), $A_{c}=$ the contact area of two fluid planes $\left(\mathrm{cm}^{2}\right), d v=$ the velocity difference two fluid planes $(\mathrm{cm})$.

In this study, a fluid flow path in a porous rock is modeled as twisting capillary pipe having an irregular cross-section shape and a rough wall surface, as illustrated in Figure 1a. If the flowing fluid is a single phase and incompressible, owing in steady state condition and laminar region, then the distribution of flow velocity happens, where the closer to the center of the pipe, the greater the flow velocity. According to Newton's viscosity law and fractal concept, for the fluid flow in a pipe as illustrated in Figure 1a, an equation of shear force on a unit volume of fluid with radius of $\ell$ (Figure 1c)

$$
F_{s}=\Delta p(2 \ell)^{D p}=-\mu(2 \ell)^{D s} L_{e} \frac{d v}{d \ell}
$$

where $d$ is the pipe diameter, $D p$ is the fractal dimension of pipe crossection area, $D s$ is the fractal dimension of pipe surface, $L_{e}$ is the pipe length, and $\Delta p$ is the pressure drop over the pipe length $L_{e},(2 \ell)^{D p}$ or $\delta^{D p}$ is the cross-section area of the unit-volume with a radius of $\ell\left(\mathrm{cm}^{2}\right),(2 \ell)^{D s}$ or $\delta^{D s}$ is the perimeter of the unit-volume with radius of $\ell(\mathrm{cm})$.

By changing $2 \ell$ with $\delta$ and $2 d \ell$ with $d \delta$, Eq. (2) can be rewritten as:

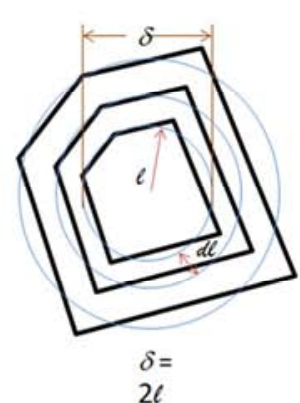

(c)

Figure 1. (a) Simplified capillary pipe model, (b) Crossection of capillary pipe model, (c) Unit-volume crossections of flowing fluid.

Then separating $\delta$ and $v$ and integrating from $v=0$ at $d$, and $v=v$ at $\delta$

$$
\frac{\Delta P}{2 \mu L_{e}} \int_{d}^{\delta} \delta^{D p-D s} d \delta=-\int_{0}^{v} d v
$$

yield the following:

$$
\frac{\Delta P}{2 \mu L_{e}}\left[\frac{\delta^{D p-D s+1}}{D p-D s+1}-\frac{d^{D p-D s+1}}{D p-D s+1}\right]=-v, \text { or } v=\frac{\Delta P}{2 \mu L_{e}}\left[\frac{d^{D p-D s+1}-\delta^{D p-D s+1}}{D p-D s+1}\right]
$$

The flow rate through the annulus between tubes with

radius $\ell$ and $\ell+d \ell$ is: 


$$
d Q_{p}=v(2 \ell)^{D s} d \ell=\frac{v \delta^{D s}}{2} d \delta
$$

Finally, integrating $d Q_{p}$ to obtain total flow rate of fluid in the pipe with length $L_{e}$ and radius $r($ diameter $=d$ ) results in a fractal equation of fluid flow in pipe:

$$
Q_{p}=\frac{d^{D p+2}}{4 \mu(D p+2)(D s+1)}\left[\frac{\Delta p}{L_{e}}\right]
$$

\subsection{Permeability Equation for Fractal Porous Media}

In this study, the pore network is modeled as an orthogonal intersecting of twisting capillary pipes, irregular crosssection shape and rough wall surface, as illustrated in Figure 2. The differences in shape and size of the capillary pipes between each orthogonal direction represent the permeability anisotropy of the actual pores network.

In $i$-direction, with a cross-section area $A_{i}$, there are $n_{i}$ capillary pipes with equal length of $L_{e i}$, so that Eq. (6) can be rewritten as follows:

$$
Q_{i}=\frac{n_{i} d_{i}^{D p_{i}+2}}{4 \mu\left(D p_{i}+2\right)\left(D s_{i}+1\right)\left(L_{e i} / L_{i}\right)}\left[\frac{\Delta p_{i}}{L_{i}}\right]
$$

Based on the assumption that not all of the pore space are active or conductive for a fluid to flow, then the active porosity in $i$-direction can be represented by:

$$
\varphi_{a i}=\frac{n_{i} d_{i}^{D p_{i}}\left(L_{e i} / L_{i}\right)}{A_{i}} \text { or } A_{i}=\frac{n_{i} d_{i}^{D p_{i}}\left(L_{e i} / L_{i}\right)}{\varphi_{a i}}
$$

where: $\phi_{a i}$ is the active porosity for fluid flow in $i$-direction; $d_{i}$ is diameter of a capillary pipe in $i$-direction $\left(\mathrm{cm}^{2}\right), n_{i}$ is the number of capillary pipes in $i$-direction; $D p_{i}$ is the fractal dimension of the pore cross-section in $i$-direction; $D s_{i}$ is the fractal dimension of the pore surface in $i$-direction; $L_{i}$ is the macroscopic length of the porous rock in $i$-direction $(\mathrm{cm}) ; L_{e i}$ is the average length of the capillary pipes in $i$-direction $(\mathrm{cm})$.

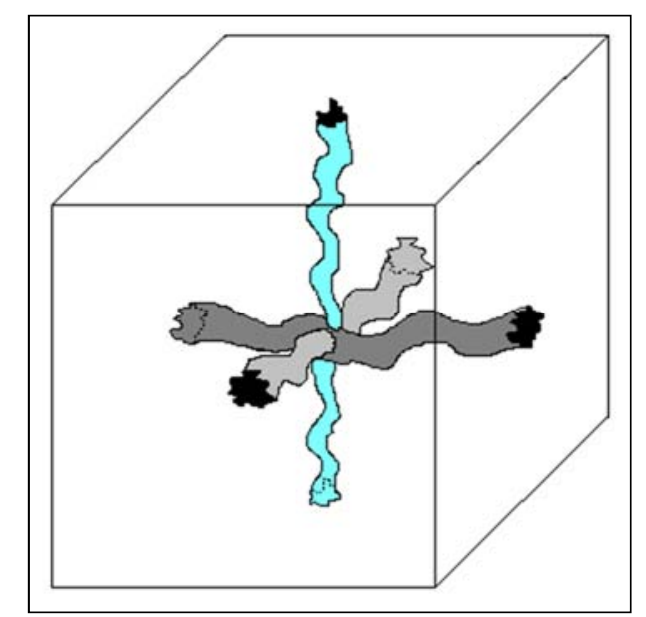

Figure 2. 3-D model of pore network of porous rock: three capillary pipes with different size, shape, and length represent the pore system in $x$-, $y$-, and $z$-directions respectively.
Defining the fraction of active pores as the ones that contribute to fluid flow in $i$-direction with the following equation:

$$
f_{a i}=\frac{\varphi_{a i}}{\varphi}
$$

where $\phi$ is the rock effective porosity (fraction), which is porosity excluding fully isolated pores, having Darcy equation below:

$$
Q_{i}=\frac{k_{i} A_{i} \Delta P_{i}}{\mu L_{i}}
$$

and finally combining Eqs. (7), (8), (9), and (10) gives a permeability equation for $i$-direction:

$$
k_{i}=\frac{f_{a i} \varphi d_{H i}^{2}}{4\left(\frac{L_{e i}}{L_{i}}\right)^{2}\left(D p_{i}+2\right)\left(D s_{i}+1\right)}
$$

where $k_{i}$ is the permeability in $i$-direction $\left(\mathrm{cm}^{2}\right),\left(L_{e i} / L_{i}\right)^{2}$ is the tortuosity in $i$-direction, and $d_{H i}$ (see Eq. (16) and Eq. (17) in Section 3 below) is the average hydraulic diameter in $i$ direction $(\mathrm{cm})$.

In $i$-direction, the relationship between tortuosity $(\tau)$ and fractal dimension of pores based on the image of a rock thin section is approximated by:

$$
\tau_{i}=\left(\frac{L_{e i}}{L_{i}}\right)^{2} \cong\left(\frac{D p_{m}}{D p_{i}}\right)^{2}
$$

where $D p_{m}$ is the fractal dimension of ideal pore model, i.e. pore model having tortuosity of 1.0 , calculated by [31]:

$$
D p_{m}=2.0444 \phi^{0.1061}
$$

Substitution of Eq. (12) into Eq. (11) and conversion of both permeability unit from $\mathrm{cm}^{2}$ to millidarcy and average hydraulic diameter from $\mathrm{cm}$ to micron $(\mu \mathrm{m})$ lead Eq. (11) to the following equation:

$$
k_{i}=\frac{1.013,274 f_{a i} \varphi d_{H i}^{2}}{4\left(\frac{D p_{m}}{D p_{i}}\right)^{2}\left(D p_{i}+2\right)\left(D s_{i}+1\right)}
$$

It is assumed here that Mercury Intrusion Capillary Pressure (MICP) provides the data of pore size distribution which is independent of the direction of injection. Consequently, hydraulic diameter $d_{H}$ obtained from MICP data analysis is a bulk property $d_{H b u l k}$. At this point, two bulk properties obtained, i.e. porosity ( $\phi)$ and $d_{\text {Hbulk }}$.

Furthermore, as described above, there are some other factors that may influence permeability. These include micropores [5], pore dead-ends or blind pores [3, 8], symmetrybypassed pores [34], and pore body-pore throat constrictions 
[7]. Since no means is available at present for determining the fractions of all such pore geometrical features, only micropores is considered and can be derived from mercury intrusion capillary pressure (MICP) measurements. It is assumed herein that micropores of less than one micron in size would not contribute to fluid flow by considering that such a pore size exists at least partly due compression porosity artifact [35]. Thus, it is defined below for the volume fraction of active pores that contribute to fluid flow in $i$-direction,

$$
\mathrm{f}_{\mathrm{ai}} \equiv 1-\mathrm{f}_{\mathrm{m}}-\mathrm{f}_{\text {dei }}-\mathrm{f}_{\mathrm{bi}} \equiv 1-\mathrm{f}_{1 \mu \mathrm{m}}
$$

where $f_{m}$ is a volume fraction of micro-pores; $f_{d e i}$ is a volume fraction of pore dead ends in $i$-direction; $f_{b i}$ is a volume fraction of symmetry-bypassed pores in $i$-direction; and $f_{l \mu m}$ is the volume fraction of pores with sizes of less than 1 micron $(\mu \mathrm{m})$. In this study, $f_{d e i}$ and $f_{b i}$ are both assumed to be zero.

If it is expected that the variable $\left(1-f_{l \mu m}\right)$ would not suffice due to the fact that pore dead ends, symmetry-bypassed pores and the likes could not be ignored for some cases, then a new parameter is introduced, that is pore geometry and structure correction factor, $f_{p g s}$, so that the component $f_{a i} \phi d^{2}{ }_{H i}$ in Eq. (14) becomes:

$$
f_{a i} \phi d^{2}{ }_{H i}=f_{\text {pgsi }}\left(1-f_{l \mu m}\right) \phi d^{2}{ }_{H b u l k}
$$

As will be discussed later, $f_{p g s}$ is an adjustment for the calculated permeability to approach the actual measured permeability. Interestingly, it is found that $f_{p g s}$ is a linear adjustment and its magnitude depends on the range of permeability values for the samples used.

\section{Samples Source and Preparation}

This study employed eighteen sandstone samples taken from whole cores of the Menggala and Bekasap Formations of Miocene age located in the Central Sumatra Basin. Porosity and permeability of the samples range from 21 to $37 \%$ and 2.76 to 3,644 millidarcies, respectively. Table 1 shows sample number, formation, lithology, and grain size of each sample. All the samples were prepared in the shape of a cube having the same size of length, width, and height, $2.10 \mathrm{~cm}$. A special rubber sleeve was made in order to be able to measure the porosity and permeability in each orthogonal direction $(x, y$, and $z)$ using computerized Ultra-Pore 300 porosimeter and Ultra-Perm 400 permeameter, respectively. Nitrogen gas was used as the fluid. It should be noted here that $x$ - and $y$-directions are parallel with the bedding plane of the Formations and $z$-direction is perpendicular to the bedding plane.

After measuring porosity and directional permeability on each sample as needed, each side of the sample was sliced as thin as $0.3 \mathrm{~mm}$ for thin-section preparation. A total of 108 thinsections were made. Every thin-section was then photographed by utilizing a digital camera coupled with a microscope having capability of magnifying more than 150 times. This set-up was connected to a computer to record the data of digital images and display on the screen to control the position of an area for taking the picture. In order to cover a large enough area of a given thin-section for a better resolution as possible for fractal analysis, it was decided to take a photograph on every area of 5 $\mathrm{mm}$ by $5 \mathrm{~mm}$, resulting in as many as 48 photos or more taken for each thin-section. Examples of thin-section photographs of sample $\# 10$ and sample $\# 16$ in $x$-, $y$-, and $z$-directions are shown in Figure 3 and Figure 4.

Table 1. Sample Number, Formation, Lithology, and Grain Size of the 18 Samples Used in this Study.

\begin{tabular}{llll}
\hline Sample & Formation & Lithology & Grain Size \\
\hline Number & Bekasap & Shally Sandstone & medium silt - fine sandstone \\
2 & Menggala & Shally Sandstone & very fine - very coarse sandstone \\
3 & Bekasap & Shally Sandstone & medium silt - coarse sandstone \\
4 & Bekasap & Shally Sandstone & medium silt - fine sandstone \\
5 & Bekasap & Shally Sandstone & coarse silt - very coarse s.s. \\
6 & Menggala & Shally Sandstone & very fine s.s - coarse s.s \\
7 & Menggala & Shally Sandstone & very fine s.s - coarse s.s \\
8 & Menggala & Shally Sandstone & very fine s.s - very coarse s.s \\
9 & Bekasap & Shally Sandstone & lanau medium - pasir halus \\
10 & Bekasap & Shally Sandstone & medium silt - fine sandstone \\
11 & Menggala & Shally Sandstone & very fine s.s - very coarse s.s \\
12 & Bekasap & Shally Sandstone & fine silt - coarse sandstone \\
13 & Bekasap & Shally Sandstone & medium silt - coarse sandstone \\
14 & Bekasap & Shally Sandstone & very fine s.s - very coarse s.s \\
15 & Bekasap & Shally Sandstone & medium silt - fine sandstone \\
16 & Bekasap & Shally Sandstone & very fine s.s - coarse s.s. \\
17 & Bekasap & Shally Sandstone & coarse silt - very coarse s.s. \\
18 & Bekasap & Shally Sandstone & medium silt - coarse sandstone \\
\hline
\end{tabular}



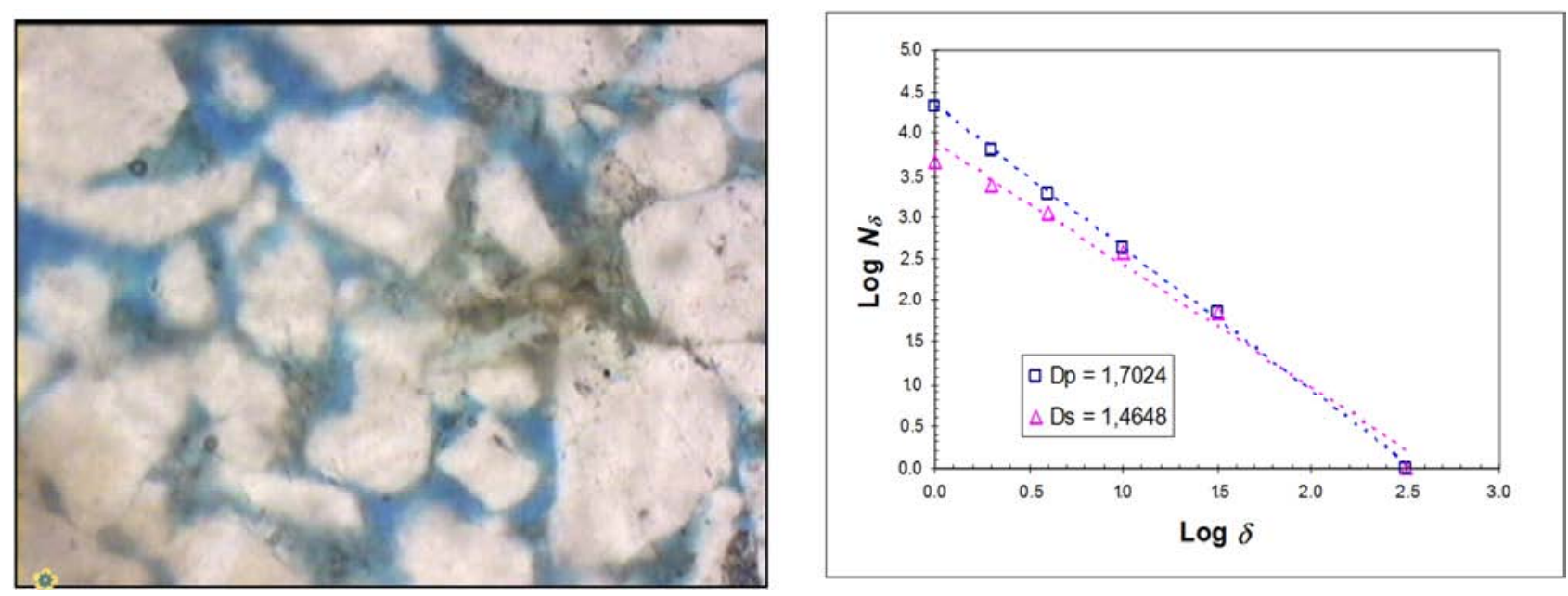

(a) $x$-direction
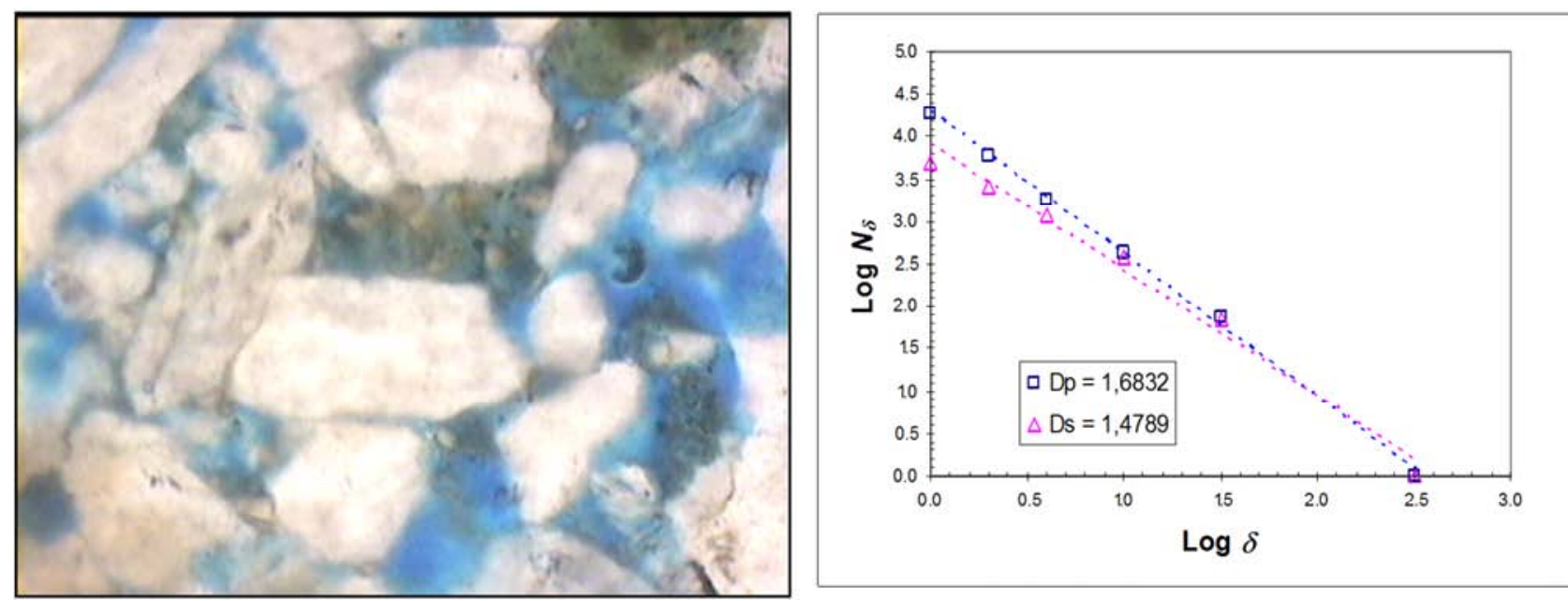

(b) $y$-direction
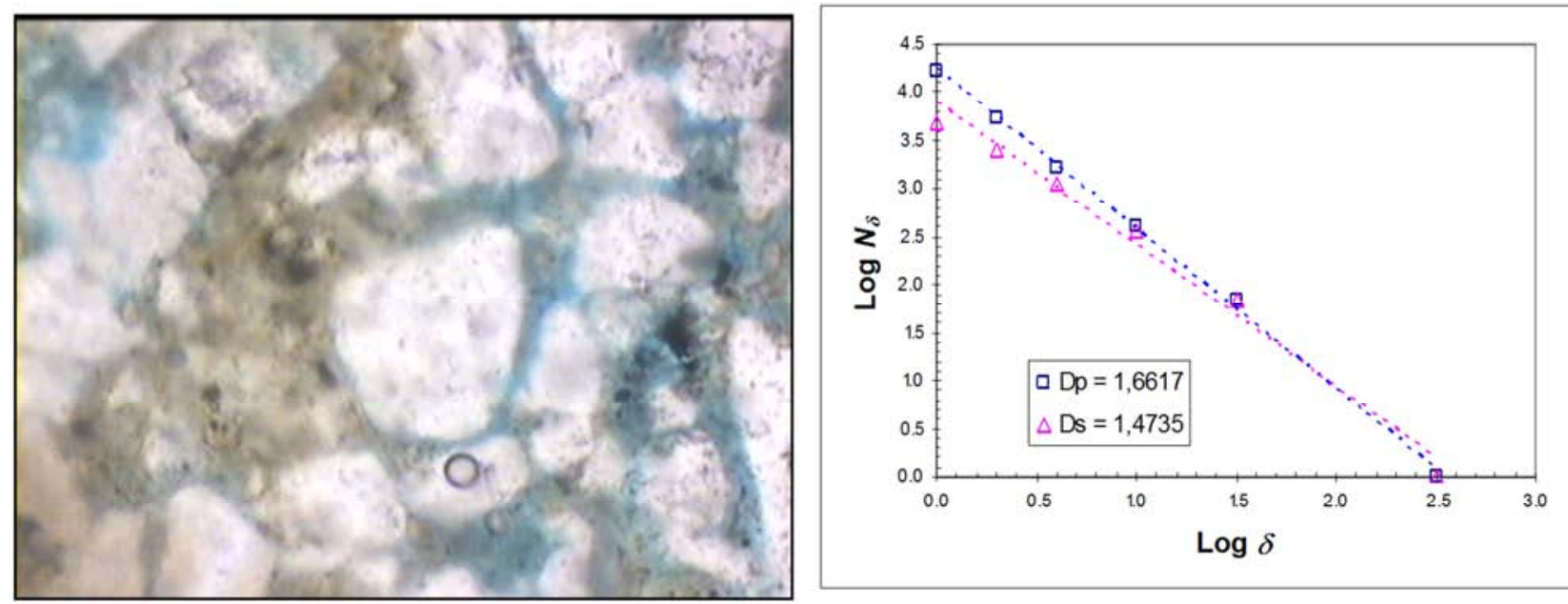

(c) $z$-direction

Figure 3. Thin-section photomicrographs and its box counting results of Sample \#10 in $x$-, $y$-, and $z$-directions (with $66 x$ magnification), $k_{x}=298.98 m D, k_{y}=$ $260.74 \mathrm{mD}, k_{z}=181.43 \mathrm{mD}$. 

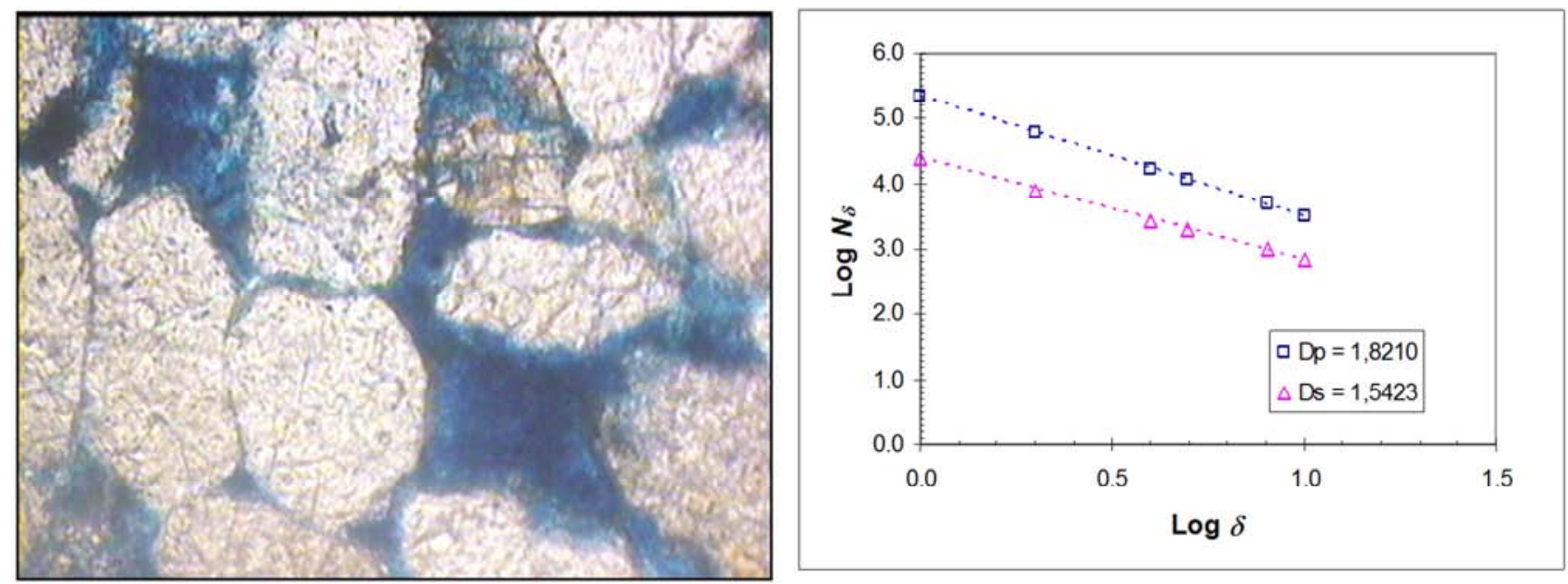

(a) $x$-direction
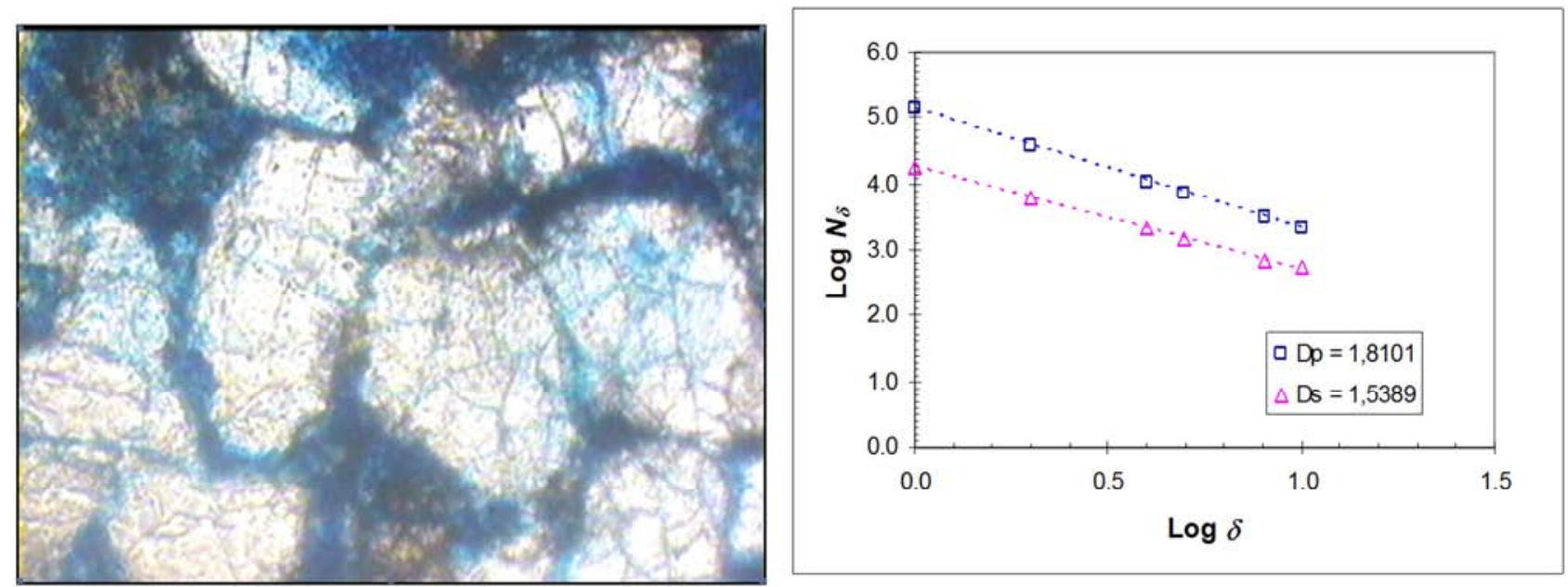

(b) $y$-direction
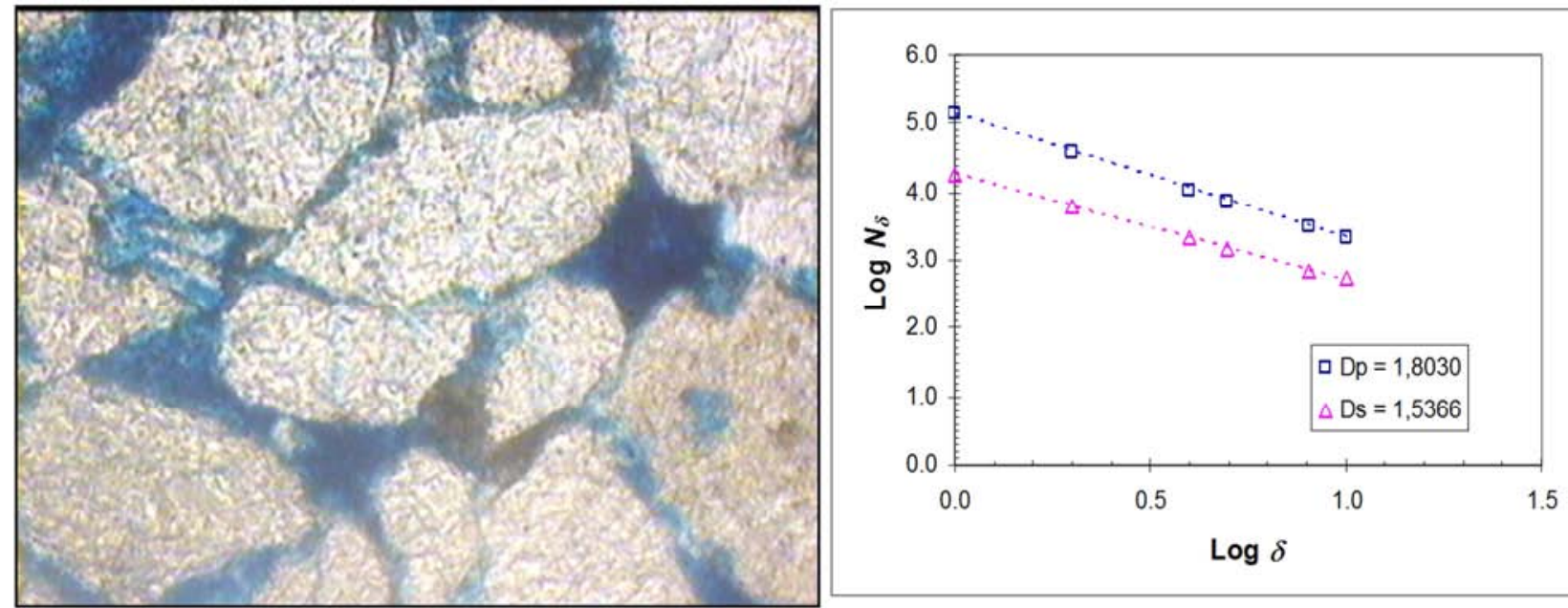

(c) $z$-direction

Figure 4. Thin-section photomicrographs and its box counting results of Sample \#16 in $x$-, $y$-, and $z$-directions (with $66 x$ magnification), $k_{x}=3,398.00 \mathrm{mD}, \boldsymbol{k}_{y}$ $=3,193.00 \mathrm{mD}, k_{z}=2,612.00 \mathrm{mD}$.

The last task was to perform capillary pressure measurements to obtain pore size distribution data for every rock sample employed. This purpose is to determine the effective hydraulic diameter $d_{\text {Hbulk }}$ and the fraction of micropores $f_{m}$ required to use Eq. (16) and Eq. (15). A computerized Micromeritics Autopore III provided with an 
Autopore III-9420 analyzer software was utilized. The apparatus has 4 low pressure ports and 2 high pressure chambers that can be operated individually or simultaneously up to 60,000 psia. Using mercury as the non-wetting fluid, the pore size distribution that can be obtained ranges from 3.6 to 360 microns for low pressure and 0.003 micron to 6 microns for high pressure. The pore size data obtained are in the forms of frequency and cumulative frequency distributions.

Since some of the sandstones used here show multimodal distribution, estimation of the effective hydraulic diameter $d_{\text {Hbulk }}$ is based on volumetric average as follows [32]:

$$
d_{H}=\frac{\sum f_{j} d_{m j}}{\sum f_{j}}
$$

where $f_{j}$ is a volume fraction of pores with $j$-mode and $d_{m j}$ is $j$-mode. The use of Eq. (17) for calculating $d_{\text {Hbulk }}$ for all the samples results in values ranging from 3.82 to 23.62 microns as given in Table 2 .

The fraction of macropores $\left(1-f_{m}\right)$ obtained for each of the samples are also presented in Table 2. This table shows that the fraction of macropores for all the sandstone samples ranges from 0.25 to 0.80 . The fraction tends to increase with permeability.

\section{Determination of Fractal Dimension}

Fractal dimensions for pore cross-section and pore wall (surface) were determined utilizing a box counting method. A BOX COUNTING software was created by using $\mathrm{C}++$ Builders language to process multi thin-section images in a single run. Fractal analysis was then performed on the 2-D thin-section images made. Examples of fractal analysis results for sample \#10 and sample \#16 in $x$-, $y$-, and $z$ directions are shown in the right side of Figures 3 and 4.

Fractal dimensions obtained for pore cross-section $D_{p}$ and pore wall surface $D_{s}$ range from 1.60 to 1.80 and 1.43 to 1.68 , respectively, as presented in Table 2 .

\section{Results and Discussion}

The sandstone samples used in this study provide a quite wide range of both porosity and permeability. These may represent various degrees of pore structure complexity. As noted above, $x$ - and $y$-directions are those parallel with the bedding plane and $z$-direction is the one perpendicular to the bedding plane. It is observed in Table 2 that permeability in $z$-direction, $k_{z}$, are significantly lower than both $k_{x}$ and $k_{y}$ for lower permeability samples. As expected that the values of $D_{p}$ for each sample are higher than $D_{s}$ correspondingly as shown in Table 2. This is because $D_{p}$ deals with the area of cross-section of pores, while $D_{s}$ relates to perimeter of solid parts.

These results are similar to those of Meng [36], showing that fractal dimension of property area is higher than that of property perimeter. Typically, he shows that measured fractal dimensions of both the sandstone pore perimeter and surface, respectively, range from 1.32 to 1.66 and 1.90 to 1.99 , depending on the scale resolution. A higher resolution yields a larger fractal dimension. In a comparison with the present study, although both the sandstone samples and the technique of determining fractal properties are different, the results of the fractal dimensions as reported above are comparable.

In the context of permeability anisotropy, it may be expected that fractal dimension of pores $D_{p}$ for $x$-direction would be higher than those for other orthogonal directions. This is because the higher the permeability, the greater and simpler the pore geometry. It is found here that only some samples, Nos. 3, 6, 7 and 10 for examples in Table 2, exhibit what is expected where $D_{p}$ for $x$-direction $>D_{p}$ for $y$ direction $>D_{p}$ for $z$-direction. Many others, however, are not obvious due to probably the pore structure complexity that will be discussed below.

Table 2 also presents the values of tortuosity ranging from about 1.03 to 1.20 determined by using Eqs. (13) and (12). It seems that the values are too low. Even though, the same methodology for determining tortuosity, $\tau$, as described above has been previously used for other sandstones and limestones, yielding $\tau$ between 1.56 and 2.76 [21]. These values are within the normal range for real porous rocks [4, 37]. It may imply then that the sandstones under the present study have much simpler pore geometry than those previously employed.

Estimation of permeability for all the samples is carried out using Eq. (14) with the related data presented in Table 2. The results obtained are given in Figures 5 (a), (b), and (c) for $k_{x}, k_{y}$, and $k_{z}$, respectively. As can be seen in these figures, except for very high permeability samples, the calculated permeability is higher than the measured one. Interestingly, the deviation gets higher as permeability is reduced and it seems then that the data points may be separated into three groups, high $(>1.500 \mathrm{mD})$, medium $(100-1.500 \mathrm{mD})$, and low permeability $(<100 \mathrm{mD})$, as already differentiated with different symbols. Such a clear separation is probably due to some factors that contribute to the complexity of pore structures. Since the highest deviation is produced by the low permeability group, it may indicate that the lower the permeability, the higher the degree of pore structure complexity. In estimating $k_{x}$ and $k_{y}$ of the high permeability group, the results demonstrate the superiority of Eq. (14). However, observation of Figure 5 (c) shows that $k_{z}$ estimated for the high permeability group is slightly off higher than the corresponding measured one. Such an indication is even worst for both medium and low permeability groups. This suggests that, for the sandstones used here, pore structure along $z$-direction is clearly distinguishable from that for $x$ and $y$-direction. The difference tends to be greater as permeability decreases. 
Table 2. The Physical and Fractal Properties in $x$-, $y$-, and z-Directions of the 18 Sandstone Samples.

\begin{tabular}{|c|c|c|c|c|c|c|c|c|c|c|}
\hline \multirow{2}{*}{$\begin{array}{l}\text { Sample } \\
\text { Number }\end{array}$} & \multirow{2}{*}{ Formation } & \multirow{2}{*}{$\begin{array}{l}\phi_{\text {plug }} \\
\text { (fraction) }\end{array}$} & \multirow{2}{*}{$\begin{array}{l}\boldsymbol{k}_{\text {plug }} \\
(\mathrm{mD})\end{array}$} & \multirow{2}{*}{$\begin{array}{l}k_{b o x} \\
(\mathrm{mD})\end{array}$} & \multirow{2}{*}{$D p$} & \multirow{2}{*}{ Ds } & \multirow{2}{*}{$\left(L_{e} / L\right)^{2}$} & \multirow{2}{*}{$\frac{(D p+2)}{x(D s+1)}$} & \multirow{2}{*}{$\begin{array}{l}d_{\text {Hbulk }} \\
(\mu \mathrm{m})\end{array}$} & \multirow{2}{*}{$\begin{array}{l}\left(1-f_{m}\right) \\
\text { (fraction) }\end{array}$} \\
\hline & & & & & & & & & & \\
\hline $1-x$ & Bekasap & 0.26 & 48.94 & 31.65 & 1.6507 & 1.5169 & 1.1319 & 9.1884 & 5.34 & 0.58 \\
\hline $\mathrm{y}$ & Bekasap & 0.26 & & 25.16 & 1.6916 & 1.5146 & 1.0704 & 9.2829 & 5.34 & 0.58 \\
\hline $\mathrm{z}$ & Bekasap & 0.26 & & 13.09 & 1.6478 & 1.5168 & 1.1172 & 9.1807 & 5.34 & 0.58 \\
\hline $2-x$ & Menggala & 0.21 & 42.80 & 68.29 & 1.7343 & 1.5056 & 1.0717 & 9.3567 & 7.53 & 0.57 \\
\hline y & Menggala & 0.21 & & 41.78 & 1.6788 & 1.4916 & 1.0877 & 9.1661 & 7.53 & 0.57 \\
\hline $3-x$ & Bekasap & 0.27 & 16.33 & 11.08 & 1.6750 & 1.5284 & 1.1082 & 9.2919 & 3.82 & 0.39 \\
\hline $\mathrm{y}$ & Bekasap & 0.27 & & 5.16 & 1.6571 & 1.5720 & 1.1492 & 9.4061 & 3.82 & 0.39 \\
\hline $\mathrm{z}$ & Bekasap & 0.27 & & 2.76 & 1.6374 & 1.5190 & 1.1338 & 9.1626 & 3.82 & 0.39 \\
\hline $4-x$ & Bekasap & 0.23 & 18.59 & 31.38 & 1.5800 & 1.5291 & 1.1873 & 9.0542 & 7.12 & 0.25 \\
\hline $\mathrm{y}$ & Bekasap & 0.23 & & 26.92 & 1.6060 & 1.5171 & 1.1863 & 9.0767 & 7.12 & 0.25 \\
\hline $\mathrm{z}$ & Bekasap & 0.23 & & 9.72 & 1.6033 & 1.5267 & 1.1676 & 9.1045 & 7.12 & 0.25 \\
\hline $5-x$ & Bekasap & 0.37 & 43.55 & 93.04 & 1.7805 & 1.5462 & 1.0824 & 9.6260 & 6.34 & 0.49 \\
\hline $\mathrm{z}$ & Bekasap & 0.37 & & 36.59 & 1.7795 & 1.6079 & 1.0738 & 9.8567 & 6.34 & 0.49 \\
\hline $6-x$ & Menggala & 0.30 & 211.76 & 100.34 & 1.7239 & 1.5138 & 1.0859 & 9.3610 & 6.92 & 0.54 \\
\hline $\mathrm{y}$ & Menggala & 0.30 & & 83.34 & 1.7176 & 1.5144 & 1.0862 & 9.3476 & 6.92 & 0.54 \\
\hline $\mathrm{z}$ & Menggala & 0.30 & & 56.88 & 1.7047 & 1.5027 & 1.0876 & 9.2716 & 6.92 & 0.54 \\
\hline $7-x$ & Menggala & 0.22 & 101.01 & 139.14 & 1.6991 & 1.5164 & 1.1165 & 9.3084 & 7.17 & 0.62 \\
\hline $\mathrm{y}$ & Menggala & 0.22 & & 114.17 & 1.6731 & 1.5200 & 1.1264 & 9.2562 & 7.17 & 0.62 \\
\hline $\mathrm{z}$ & Menggala & 0.22 & & 51.07 & 1.6728 & 1.5148 & 1.1186 & 9.2364 & 7.17 & 0.62 \\
\hline $8-x$ & Menggala & 0.26 & 158.06 & 186.44 & 1.7295 & 1.5039 & 1.0876 & 9.3383 & 7.53 & 0.72 \\
\hline $\mathrm{y}$ & Menggala & 0.26 & & 175.16 & 1.7043 & 1.5053 & 1.0829 & 9.2804 & 7.53 & 0.72 \\
\hline $\mathrm{z}$ & Menggala & 0.26 & & 174.43 & 1.7158 & 1.5000 & 1.0632 & 9.2895 & 7.53 & 0.72 \\
\hline $9-x$ & Bekasap & 0.26 & 186.37 & 217.17 & 1.7047 & 1.4856 & 1.0903 & 9.2086 & 10.07 & 0.55 \\
\hline y & Bekasap & 0.26 & & 214.73 & 1.7321 & 1.5074 & 1.0303 & 9.3578 & 10.07 & 0.55 \\
\hline $\mathrm{z}$ & Bekasap & 0.26 & & 185.31 & 1.7006 & 1.4874 & 1.0463 & 9.2048 & 10.07 & 0.55 \\
\hline $\mathrm{z}$ & Bekasap & 0.24 & & 181.43 & 1.6617 & 1.4735 & 1.0959 & 9.0572 & 9.08 & 0.56 \\
\hline $11-x$ & Menggala & 0.29 & 283.06 & 310.11 & 1.7147 & 1.4668 & 1.0906 & 9.1635 & 13.14 & 0.57 \\
\hline $\mathrm{y}$ & Menggala & 0.29 & & 275.58 & 1.7119 & 1.4941 & 1.0881 & 9.2579 & 13.14 & 0.57 \\
\hline $\mathrm{z}$ & Menggala & 0.29 & & 93.96 & 1.7266 & 1.4751 & 1.0882 & 9.2238 & 13.14 & 0.57 \\
\hline $12-x$ & Bekasap & 0.29 & 394.51 & 410.70 & 1.6438 & 1.5543 & 1.2048 & 9.3074 & 16.01 & 0.58 \\
\hline y & Bekasap & 0.29 & & 343.27 & 1.7283 & 1.5518 & 1.0462 & 9.5138 & 16.01 & 0.58 \\
\hline $\mathrm{z}$ & Bekasap & 0.29 & & 248.47 & 1.6914 & 1.5300 & 1.1202 & 9.3392 & 16.01 & 0.58 \\
\hline $13-x$ & Bekasap & 0.33 & $1,191.58$ & $1,301.32$ & 1.7451 & 1.5021 & 1.0871 & 9.3708 & 19.57 & 0.67 \\
\hline y & Bekasap & 0.33 & & $1,111.05$ & 1.7433 & 1.5031 & 1.0861 & 9.3698 & 19.57 & 0.67 \\
\hline $\mathrm{z}$ & Bekasap & 0.33 & & 576.94 & 1.7270 & 1.4798 & 1.0878 & 9.2421 & 19.57 & 0.67 \\
\hline $14-x$ & Bekasap & 0.37 & $1,789.30$ & $1,606.98$ & 1.7358 & 1.6470 & 1.1013 & 9.8887 & 14.15 & 0.86 \\
\hline y & Bekasap & 0.37 & & $1,411.17$ & 1.7459 & 1.6388 & 1.1013 & 9.8847 & 14.15 & 0.86 \\
\hline z & Bekasap & 0.37 & & $1,380.49$ & 1.7331 & 1.5245 & 1.0912 & 9.4242 & 14.15 & 0.86 \\
\hline $15-x$ & Bekasap & 0.29 & $1,858.70$ & $1,933.17$ & 1.7259 & 1.5166 & 1.0126 & 9.3766 & 19.10 & 0.78 \\
\hline y & Bekasap & 0.29 & & $1,209.47$ & 1.6286 & 1.5115 & 1.0624 & 9.1132 & 19.10 & 0.78 \\
\hline $\mathrm{z}$ & Bekasap & 0.29 & & $1,162.97$ & 1.7798 & 1.5420 & 1.0340 & 9.6083 & 19.10 & 0.78 \\
\hline $16-x$ & Bekasap & 0.33 & $3,361.80$ & $3,398.00$ & 1.8120 & 1.5423 & 1.0081 & 9.6912 & 23.62 & 0.73 \\
\hline y & Bekasap & 0.33 & & $3,193.00$ & 1.8101 & 1.5389 & 1.0184 & 9.6735 & 23.62 & 0.73 \\
\hline $\mathrm{z}$ & Bekasap & 0.33 & & $2,612.00$ & 1.8030 & 1.5366 & 1.0069 & 9.6467 & 23.62 & 0.73 \\
\hline $17-x$ & Bekasap & 0.37 & $3,021.21$ & $3,737.91$ & 1.7075 & 1.6875 & 1.1459 & 9.9639 & 23.04 & 0.80 \\
\hline y & Bekasap & 0.37 & & $3,504.86$ & 1.7248 & 1.5983 & 1.1209 & 9.6781 & 23.04 & 0.80 \\
\hline $\mathrm{z}$ & Bekasap & 0.37 & & $3,350.94$ & 1.7455 & 1.6320 & 1.1031 & 9.8582 & 23.04 & 0.80 \\
\hline $18-x$ & Bekasap & 0.35 & $3,742.95$ & $3,644.80$ & 1.7496 & 1.4580 & 1.0898 & 9.2165 & 21.98 & 0.76 \\
\hline y & Bekasap & 0.35 & & $3,643.60$ & 1.7333 & 1.4554 & 1.0907 & 9.1670 & 21.98 & 0.76 \\
\hline $\mathrm{z}$ & Bekasap & 0.35 & & $2,519.72$ & 1.7571 & 1.4382 & 1.0915 & 9.1606 & 21.98 & 0.76 \\
\hline
\end{tabular}




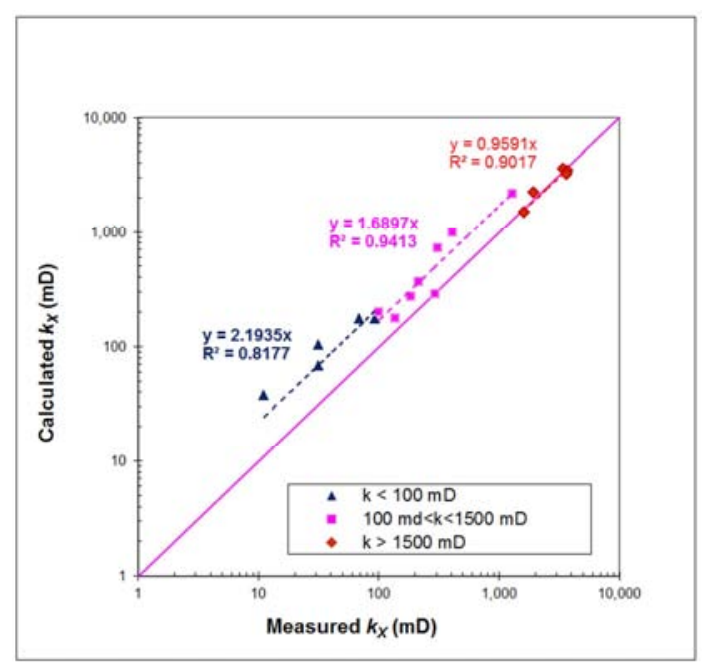

(a)

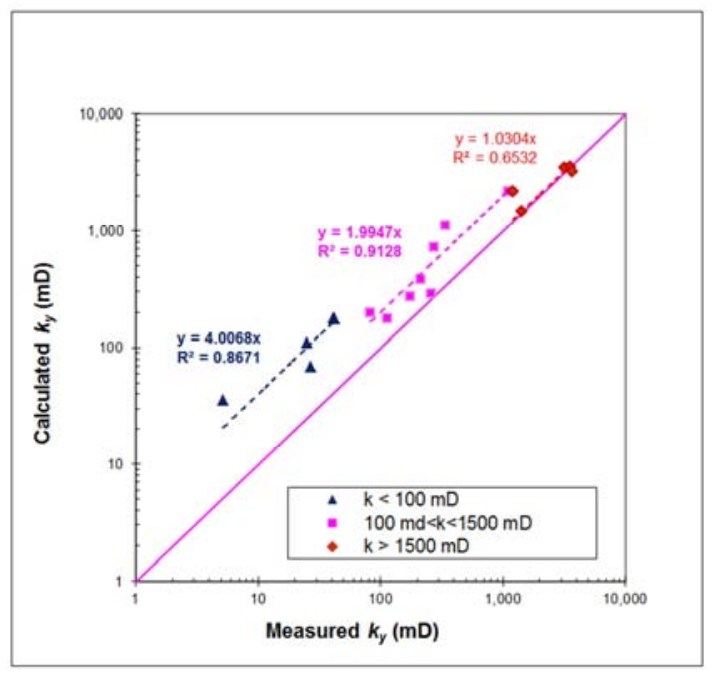

(b)

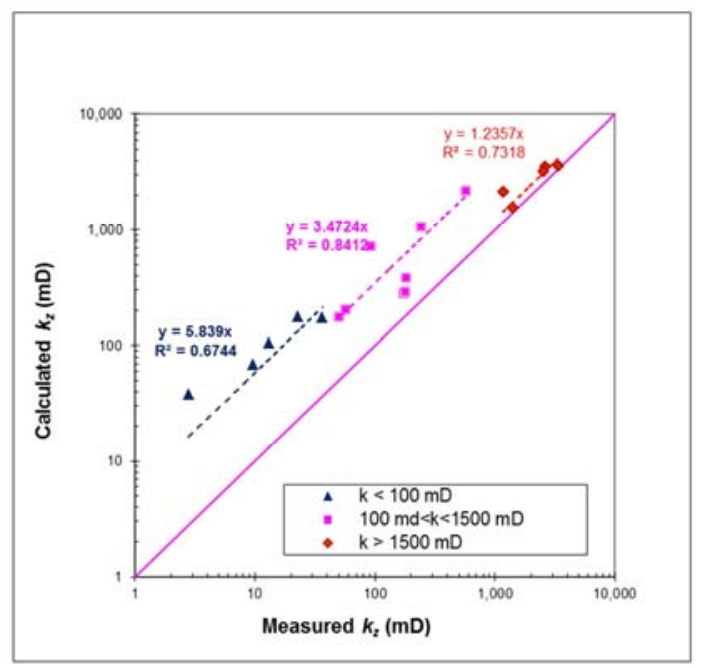

(c)

Figure 5. Plot of meassured permeability vs calculated permeability using Eq. (14) with the related data presented in Table 2: (a) in x-direction, (b) in $y$-direction, (c) in z-direction.

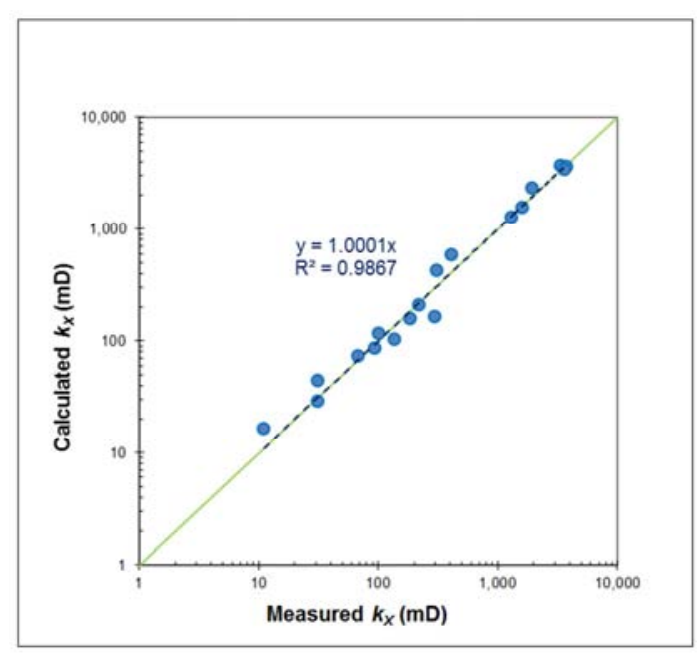

(a)

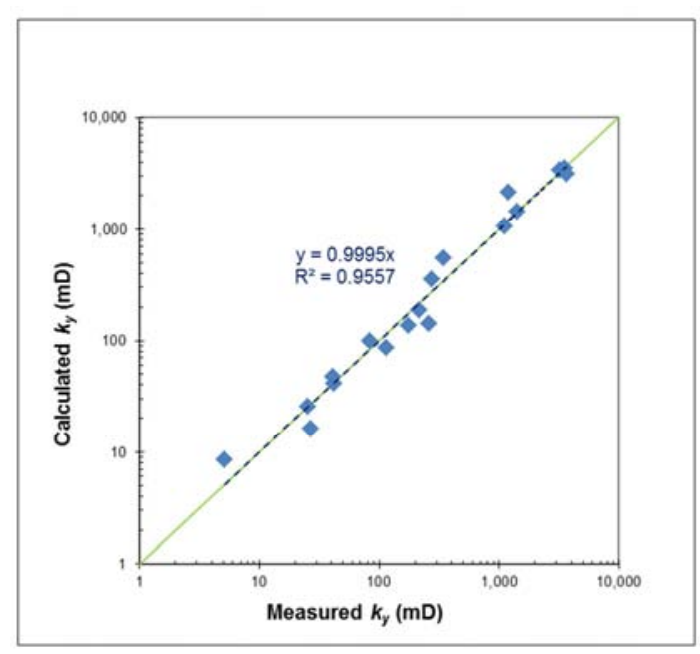

(b)

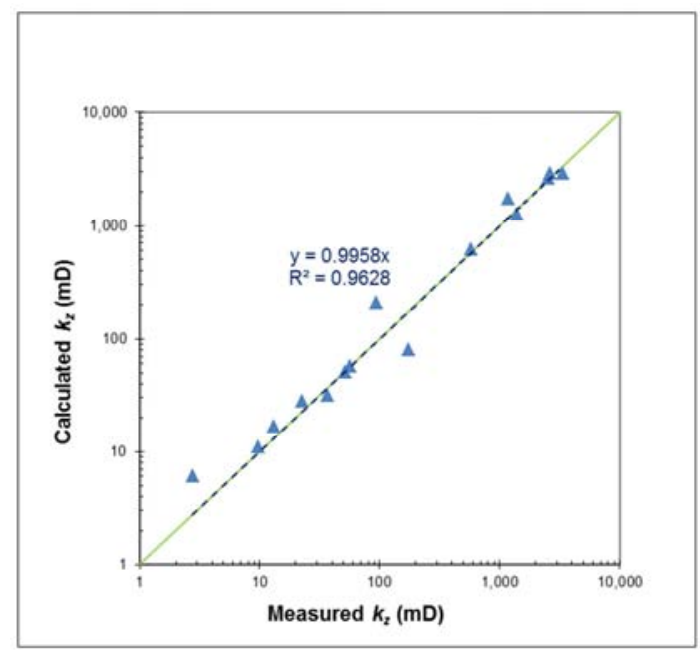

(c)

Figure 6. Plot of meassured permeability vs calculated permeability using Eq. (14) with the related data presented in Table 2 after correction with related $f_{p g s}$ values in Table 3: (a) in $x$-direction, (b) in y-direction, (c) in $z$ direction. 
Table 3. The Pore Geometry and Structure Correction Factors of the 18 Sandstone Samples.

\begin{tabular}{|c|c|c|c|c|c|c|c|}
\hline \multirow{2}{*}{$\begin{array}{l}\text { Group of } \\
\text { Sampels }\end{array}$} & \multirow{2}{*}{$\begin{array}{l}\text { Sample } \\
\text { Numbers }\end{array}$} & \multicolumn{2}{|c|}{$x$-Direction } & \multicolumn{2}{|c|}{$y$-Direction } & \multicolumn{2}{|c|}{$z$-Direction } \\
\hline & & $m$ & $f_{p g s}$ & $m$ & $f_{p g s}$ & $m$ & $f_{p g s}$ \\
\hline $\begin{array}{l}1 \\
\left(k_{x}<100 \mathrm{mD}\right)\end{array}$ & $1,2,3,4,5$ & 2.337 & 0.428 & 4.212 & 0.237 & 6.241 & 0.160 \\
\hline$\left(k_{x}=100-1500 \mathrm{mD}\right)$ & $6,7,8,9,10,11,12,13$ & 1.690 & 0.592 & 1.995 & 0.501 & 3.472 & 0.288 \\
\hline$\left(k_{x}>1500 \mathrm{mD}\right)$ & $14,15,16,17,18$ & 0.959 & 1.043 & 1.030 & 0.971 & 1.236 & 0.809 \\
\hline
\end{tabular}

Table 4. The Results of Permeability Calculation in $x$-, $y$-, and $z$-Directions Calculated by Eq. (14) through the Use of $\left(f_{a i} \phi d^{2}{ }_{H i}\right)$ Values.

\begin{tabular}{|c|c|c|c|c|c|c|c|}
\hline \multirow{2}{*}{$\begin{array}{l}\text { Sample } \\
\text { Number } \\
\end{array}$} & \multirow{2}{*}{ Formation } & \multicolumn{2}{|l|}{$x$-Direction } & \multicolumn{2}{|l|}{$y$-Direction } & \multicolumn{2}{|l|}{$z$-Direction } \\
\hline & & $\boldsymbol{k}_{\text {measured }}(\mathrm{mD})$ & $\boldsymbol{k}_{\text {calculated }(\mathrm{mD})}$ & $\boldsymbol{k}_{\text {measured }}(\mathrm{mD})$ & $\boldsymbol{k}_{\text {calculated }(\mathrm{mD})}$ & $\boldsymbol{k}_{\text {measured }}(\mathrm{mD})$ & $\boldsymbol{k}_{\text {calculated }(\mathrm{mD})}$ \\
\hline 1 & Bekasap & 31.65 & 44.28 & 25.16 & 25.68 & 13.09 & 16.80 \\
\hline 3 & Bekasap & 11.08 & 16.29 & 5.16 & 8.60 & 2.76 & 6.04 \\
\hline 4 & Bekasap & 31.38 & 28.96 & 26.92 & 16.04 & 9.72 & 10.97 \\
\hline 5 & Bekasap & 93.42 & 85.03 & 41.07 & 47.78 & 36.59 & 31.29 \\
\hline 7 & Menggala & 139.14 & 102.31 & 114.17 & 86.91 & 51.07 & 50.42 \\
\hline 8 & Menggala & 186.44 & 157.92 & 175.16 & 135.59 & 174.43 & 79.31 \\
\hline 9 & Bekasap & 217.17 & 211.83 & 214.73 & 187.63 & 185.31 & 107.97 \\
\hline 10 & Bekasap & 298.98 & 165.99 & 260.74 & 142.14 & 181.43 & 82.60 \\
\hline 11 & Menggala & 310.11 & 424.36 & 275.58 & 358.091 & 93.96 & 206.59 \\
\hline 12 & Bekasap & 410.70 & 576.24 & 343.27 & 551.63 & 248.47 & 301.70 \\
\hline 14 & Bekasap & $1,606.98$ & $1,544.47$ & $1,411.17$ & $1,438.06$ & $1,380.49$ & $1,269.65$ \\
\hline 15 & Bekasap & $1,929.84$ & $2,327.14$ & $1,207.83$ & $2,123.20$ & $1,162.66$ & $1,725.70$ \\
\hline 16 & Bekasap & $3,398.00$ & $3,673.20$ & $3,193.00$ & $3,392.87$ & $2,612.00$ & $2,870.07$ \\
\hline 17 & Bekasap & $3,737.91$ & $3,587.04$ & $3,504.86$ & $3,510.87$ & $3,350.94$ & $2,921.07$ \\
\hline 18 & Bekasap & $3,644.80$ & $3,364.00$ & $3,643.60$ & $3,142.96$ & $2,519.72$ & $2,621.08$ \\
\hline
\end{tabular}

The complexity of pore structure aforementioned may relate to factors, such as pore dead ends and other bypassed pores that could not be determined or captured by means of neither measurements nor fractal analysis that uses box counting technique. Some publications mention that inactive pore volume that hinders fluid flow could be as much as one third of total pore volume $[3,5]$ or about within the range of 0.14 to 0.68 of total pore volume [4]. Micro pores factor is already considered and discussed it in deriving Eq. (15), but it is found here that the other factors have to be handled. This is why a pore geometry and structure correction factor $\left(f_{p g s}\right)$ is proposed, as presented in Eq. (16). As just described, each permeability group needs a certain adjustment or correction that differs from the other groups. For these particular samples employed, the correction factor $f_{p g s}$ is simply $1 /$ slope obtained from the relationship of calculated permeability against measured one. For an example, the slopes obtained from Figure 5 for $k_{x}$ gives $f_{p g s}$ equal to $1.043,0.592$, and 0.428 for high, medium, and low permeability group, respectively (see Table 3 ). For the high permeability group, $f_{p g s}$ is $1.043,0.971$, and 0.809 , respectively, for $k_{x}, k_{y}$, and $k_{z}$, resulting in the ratio of $\left(f_{p g s}\right)_{x}$ to $\left(f_{p g s}\right)_{z}$ of 1.29 . This ratio may indicate the degree of the difference in directional pore structure. As the ratio is relatively low for the high permeability group, the directional pore structure is not significantly different for different flow directions. Or in other words, this high permeability group is nearly isotropic. Differently, the ratio of $f_{p g s}$ for $k_{x}$ and $k_{z}$ is as high as 2.05 and 2.67 for the medium and low permeability groups, respectively. This situation for the last two rock groups implies that the directional pore structure is considerably different for different flow directions.

Implementing the value of $f_{p g s}$ in Eq. (16) to obtain $f_{a i} \phi d_{H i}^{2}$ and then plugging this in Eq. (14) for the corresponding group produces the results as shown in Figure 6 (a) for $k_{x}$, showing the match between the calculated and the measured permeability. The rest is exhibited in Figures 6 (b) and 6 (c) for $k_{y}$ and $k_{z}$, respectively. The numerical values are presented in Table 4 .

Over all, the calculated permeability of the high permeability sandstone group is very close to the measured one and only a small correction or $f_{p g s}$ of about close to 1.0 is resulted. This may infer that this sample group contains negligible pore complexities and thus the tortuosity is relatively low as is approximated through the fractal analysis. Nevertheless, in general, a further research in the field of fractal area for estimating 3-D tortuosity, pore dead end, and the likes in particular is warranted in attempt to better characterize and determine each of those that significantly influences fluid flow. 


\section{Conclusion}

The investigation of permeability anisotropy through fractal analysis on the thin-sections has found that fractal dimension of pores, $D_{p}$, of some rock samples show a character of $D_{p}$ for $x$-direction $>D_{p}$ for $y$-direction $>D_{p}$ for $z$ direction.

An equation for estimating permeability of porous rocks has been developed by coupling the laws of Newton viscosity, Darcy fluid fow, and fractal concept. The developed equation was applied to estimating permeability of eighteen sandstone samples in three orthogonal directions.

Based on the equation developed, a pore geometry and structure correction factor $f_{p g s}$ has to be introduced to the equation to handle pore complexity that is not captured by fractal analysis. Three permeability groups, high, medium, and low, are identified to have its own respective $f_{p g s}$. The high permeability group has correction factor $f_{p g s}$ of about close to 1.0 .

A lower permeability group successively has a lower $f_{p g s}$ value. This characteristic for each group holds for orthogonal directions. This may imply in general that the complexity of pore geometry and structure gets higher as permeability decreases.

A further research in the application of fractal concept is needed to capture internal pore features such as pore tortuosity, dead ends, and other pore obstacles that affect fluid flow.

\section{Acknowledgements}

The authors would like to acknowledge the support of this work by Institute for Research and Community Service, Universitas Pembangunan Nasional "Veteran" Yogyakarta.

\section{References}

[1] Kozeny, J., Uber Kapillare Leitung des Wassers im Boden, Sitzungsberichte der Wiener Akademie der Wissenschaften, Wien, 1927, pp. 137, 271-306.

[2] Carman, P. C., Fluid Flow Through Granular Beds, Trans. Inst. Chem. Eng., London, England, 1937, pp. 15, 150-167.

[3] Scheidegger, A. E., The Physics of Flow through Porous Media, University of Toronto Press, Canada, 1959, pp. 112133.

[4] Dullien, F. A. L., Porous Media Fluid Transport and Pore Structure, Academic Press, New York, USA, 1979, pp. 75137.

[5] Bear, J., Dynamics of Fluids in Porous Media, Dover Publication, Inc, New York, USA, 1988, pp. 161-176.

[6] Srisutthiyakorn, N., and Mavko, G., An Improved KozenyCarman for Irregular Pore Geometries, Society of Exploration Geophysicists, 2015, pp. 3015-3019.

[7] Haro, C. F., Permeability Modelling in Porous Media: Setting Archie and Carman-Kozeny Right, Paper SPE 100201, Proceedings of SPE International Conference and Exhibition, Veracruz, Mexico, 27 - 30 June 2007.
[8] Krauss, E. D. and Mays, D. C., Modification of the KozenyCarman Equation to Quantify Formation Damage by Fines in Clean Unconsolidated Sandstones, Paper SPE 165148, Proceedings of the SPE European Formation Damage Conference and Exhibition, Noordwijk, Netherlands, $5-7$ June 2013.

[9] Civan, F., Relating Permeability to Pore Connectivity using a Power-Law Flow Unit Equation, Petrophysics, vol. 43, No. 6, 2002, pp. 457-476.

[10] Civan, F., Fractal Formulation of the Porosity and Permeability Relationship Resulting in Power-Law Units Equation - A Leaky Tube Model, Paper SPE 73785, Proceedings of the SPE International Symposium on Formation Damage, Lafayette, LA, USA, 23 - 24 February 2002.

[11] Civan, F., Characterization of Reservoir Flow Units Based on a Power-Law Equation of Permeability Obtained from an Interacting Bundle Leaky Tubes Model, Paper SPE 187289, Proceedings of SPE Annual Technical Conference and Exhibition, San Antonio, TX, USA, 9 - 11 October 2017.

[12] Mandelbrot, B. B., The Fractal Geometry of Nature, Freeman, San Francisco, 1982.

[13] Falconer, K., Fractal Geometry, Mathematical Foundations and Applications, John Wiley \& Sons Ltd, Baffins Lane, Chichester, West Sussex, England, 1990, pp. 3 - 53, 133-136.

[14] Katz, A. J. and Thompson, A. H., Fractal Sandstone Pores: Implications for Conductivity and Pore Formation, Phys. Rev. Lett., vol. 54, No. 12, 1985, pp. 1325-1328.

[15] Pape, H., Riepe, L., and Schopper, J. R., Theory of SelfSimilar Network Structures in Sedimentary and Igneous Rocks and Their Investigation with Microscopical Methods, Journal of Microscopy, vol. 148, 1987, pp. 121-147.

[16] Pape, H., Clauser, C., and Iffland, J., Permeability Prediction for reservoir Sandstones and Basement Rocks Based on Fractal Pore Space Geometry, SEG Expanded Abstract, 1998.

[17] Pape, H., Clausser, C., and Iffland, J., Permeabiity Prediction Based on Fractal Pore-Space Geometry, Geophysics, vol. 64, 1999, pp. 1447-1460.

[18] Pape, H., Arnold, J., Pechnig, R., Clausser, C., Talnishnikh, E., Anferova, S., and Iffland, Blümlich, B., Permeability Prediction for Low Porosity Rocks by Mobile NMR, Pure and Applied Geophysics, vol. 166, 2009, pp. 1125-1163.

[19] Hansen, J. P. and Skjeltorp, A. T., Fractal Pore Space and Rock Permeability Implications, Physical Review B, vol. 378, No. 4, 1988, pp. 2635-2638.

[20] Shen, P. and Li, K., A New Method for Determining the Fractal Dimension of Pore Structures and Its Application, Proceedings of the 10th Offshore South East Asia Conference, Singapore, 6 - 9 December 1994.

[21] Abdassah, D., Permadi, P., Sumantri, Y., and Sumantri, R, Saturation Exponent at Various Wetting Conditions: Fractal Modelling of Thin Sections, J. Petroleum Sci. \& Eng., 1998, pp. 20, 147-154.

[22] Moulu, J-C., Vizika, O., Kalaydjian, F., and Duquerroix, J-P., A New Model for Three-Phase Relative Permeabilities Based on a Fractal Representation of the Porous Media, SPE 38891, Proceedings of SPE Annual Technical Conference and Exhibition, San Antonio, TX, USA, 5 - 8 October 1997. 
[23] Civan, F., Improved Permeability Equation from the Bundleof-Leaky-Capillary-Tubes Model, Paper SPE 94271, Proceedings of SPE Production Operations Symposium, Oklahoma City, OK, USA, 17 - 19 April 2005.

[24] Li, K., Characterization of Rock Heterogeneity Using Fractal Geometry, Paper SPE 86975, SPE International Thermal Operations and Heavy Oil Symposium and Western Regional Meeting, Bakersfield, CA, USA, 16 - 18 March 2004.

[25] Xu, P. and Yu, B. M., Developing a New Form of Permeability and Kozeny-Carman Constant for Homogeneous Porous Media by Means of Fractal Geometry, Advanced Water Resources, vol. 31, No. 1, 2008, pp. 74-81.

[26] Zhang, Z. and Weller, A., Factal Dimension of Pore Space Geometry of an Eocene Sandstone Formation, Geophysics, vol. 79, No. 6, 2014, pp. 377-387.

[27] Lei, G., Dong, P., Wu, Z., Mo, S., Gai, S., Zhao, C., \& Liu, Z. K., A Fractal Model for the Stress-Dependent Permeability and Relative Permeability in Tight Sandstones, Journal of Canadian Petroleum Society, January 2015, pp. 36-48.

[28] Tiab, D. and Donaldson, E. C., Petrophysics: Theory and Practice of MeasuringReservoir Rock and Fluid Transporting Properties, Second Edition, Elsevier Inc., Gulf Professional Publishing, Massachusetts, USA, 2004.

[29] Widarsono, B., Muladi, A., and Jaya, I., Permeability Vertical-to-Horizontal Anisotropy in Indonesian Oil and Gas Reservoirs: A General Review, Paper SPE 103315, Proceedings of the First International Conference and Exhibition in Mexico, Cancun, Mexico, 31 August - 2 September 2006.
[30] Pirson, S. J., Oil Reservoir Engineering, McGraw-Hill Book Company Inc., New York, USA, Second Edition, 1958, pp. 97-103.

[31] Sumantri, Y., Permeability Anisotropy Study of Sandstone Through the Pore Size Distribution and Fractal of Thin Sections Analysis, Dissertation, Department of Petroleum Engineering, Graduate Program, Bandung Institute of Technology, 2007.

[32] Sumantri, Y., Permadi, P., and Putra, J. C. E., Estimating Permeability for Sandstones Having Multi-Modal Pore Size Distribution, Proceedings of International Geosciences Conference and Exhibition, Jakarta, Indonesia, 14 - 16 August 2006.

[33] Bear, J., Dynamics of Fluids in Porous Media, Dover Publication, Inc, New York, 1988.

[34] Perez-Rosales, C., On the Relationship between Formation Resistivity Factor and Porosity, SPE Journal, Society of Petroleum Engineers, Richardson, TX, USA, 1982, pp. 531536.

[35] Ishutov, S. and Hasiuk, F. J., 3D Printing Berea sandstone: Testing a New Tool for Petrophysical Anaysis of Reservoirs, Petrophysics, vol. 58, No. 6, 2017, pp. 592-602.

[36] Meng, B., Determination and Interpretation of Fractal Properties of the Sandstone Pore System, Materials and Structures/Materiaux et Constructions, Vol. 29, May 1996, pp. 195-205.

[37] Winsauer, W. O., Shearin, Jr., H. M., Masson, P. H., and Williams, M., Resistivity of Brine-Saturated Sands in Relation to Pore Geometry, Bull. AAPG, vol. 36, No. 2, 1952, pp. 253277. 